\title{
Development of Pig Iron and Molten Slag Level Measurement Technique for Blast Furnace
}

\author{
Tomohiko ITO, ${ }^{1{ }^{*}}$ Junichi YOTSUJ11) and Akio NAGAMUNE ${ }^{2)}$ \\ 1) JFE Steel Corp., 1-1, Minamiwataridacho, Kawasaki-ku, Kawasaki-shi, Kanagawa, 210-0855 Japan. \\ 2) JFE Techno-Research Corp., 1-1, Minamiwataridacho, Kawasaki-ku, Kawasaki-shi, Kanagawa, 210-0855 Japan.
}

(Received on March 31, 2014; accepted on July 11, 2014)

\begin{abstract}
Measurement of the pig iron and slag level in the blast furnace is essential to operate the furnace stably because an increase of these liquids level can cause fluctuations of the pressure in the furnace or the temperature of the furnace which are related to the furnace condition and may finally result in reduced productivity or serious trouble.

The conventional method is the EMF (electromotive force) measurement correlated with the liquid level. It can be thought that a voltage generated electrochemically (as in a battery) by the reduction reaction of iron oxides. However some reports said that EMF sometimes loses correlation with the liquid level because of thermal influence.

In this paper a new method is proposed using a quite small electrical resistance measurement of the hearth of a blast furnace which contains pig iron and molten slag. Accordingly the four point contact method was adopted and a pseudo random signal as a current pattern was fed to improve the S/N ratio.

Measurements were done at plural positions along the circumference of the blast furnace. However when the current signal is independently fed at each position, spike noises are generated. These noises are originated in the induced voltage which is generated at neighbor positions when the polarity of the current changes. But finally this noise problem can be solved by feeding synchronized current and measuring the signal on the noiseless timing.

The measurement results indicated that the level in the hearth is not necessary identical at all positions.
\end{abstract}

KEY WORDS: blast furnace; pig iron; molten slag; level measurement; electrical resistance; pseudo random signal.

\section{Background}

Stability is extremely important in blast furnace operation, as the blast furnace is the first upstream process in steel production. Nevertheless, increase of the pig iron and molten slag level prevents stable operation. Pig iron descends, and then accumulates in the blast furnace hearth. And also, molten slag descends to the hearth. However, the molten slag accumulates over the pig iron because its density is lower than that of iron.

Pig iron and molten slag are drained from one of plural tap holes (in the case of large blast furnaces) by turns at regular intervals. However, molten slag has poor drainage due to its relatively higher viscosity, and under special conditions when the temperature in the furnace is lower than usual, the viscosity of the molten slag increases, making tapping even more difficult. In the worst case, an excessive rise of the pig iron and molten slag level can cause serious trouble in which the molten slag melts the tuyeres. This type of trouble does not have only an adverse influence on operation over an extended time, but is also a problem for safety. Therefore, when the pig iron and molten slag level rises, pig iron and

\footnotetext{
* Corresponding author: E-mail: to-ito@jfe-steel.co.jp
} DOI: http://dx.doi.org/10.2355/isijinternational.54.2618 molten slag are drained from plural tap holes at the same time, enabling control of the productivity of pig iron and molten slag in order to keep the appropriate level and realize stable operation.

The conventional method of measuring the pig iron and molten slag level is the EMF (electromotive force) method, ${ }^{1-5)}$ in which the voltage generated in a blast furnace is detected. It is thought that the reduction reaction in the blast furnace causes the electromotive force electrochemically by a similar principle to that in dry cells. ${ }^{5)}$ Voltage changes are correlated with changes of the pig iron and molten slag level. Some reports have found a correlation between these changes, but in some cases, the results of measurement simply reflect the heat condition of the furnace, which is not correlated with the pig iron and molten slag level. ${ }^{5}$ )

Other techniques have also been reported using (1) comparison of the weights of input and output materials, ${ }^{6}$ (2) measurement of the expansion of the furnace body with strain gauges on the surface of the furnace, ${ }^{6}$ and (3) measurement of the injection pressure of $\mathrm{N}_{2}$ gas injected from a tap hole. ${ }^{6,7)}$

The authors adopted an active method in which electric resistance is measured by feeding a current in the lower part of a furnace. This is possible because all the components of 
the lower part of the furnace (pig iron, molten slag, carbon bricks) are conductors.

\section{Principle of Measurement}

The principle of measurement can be expressed as a simple equivalent circuit, ${ }^{9)}$ as showing in Fig. 1, where $r_{0}, r_{1}$ are the resistance per unit of length of the carbon bricks and molten slag, and $x_{1}, x_{2}$, and $x_{3}$ are the pig iron level (height of pig iron from the bottom of the furnace hearth), the thickness of the molten slag, and the distance from the molten slag level to the upper electrode which detects voltage, respectively.

As shown in Fig. 1, the lower electrode for detecting voltage is set at a higher position than the pig iron level. Since the boundary position between the pig iron and molten slag changes around the tap hole level, it is reasonable to assume that an electrode should be set about $500 \mathrm{~mm}$ higher than the tap hole level. The composed resistance in the equivalent circuit between two electrodes for detecting voltage is expressed by Eq. (1), where, assuming that the resistance of pig iron $<<$ the resistance of carbon brick and the resistance of molten slag

$$
R=\frac{r_{0}{ }^{2}}{r_{0}+r_{1}} L_{D O W N}+r_{0} L_{U P}-\frac{r_{0}{ }^{2}}{r_{0}+r_{1}}\left(x_{1}+x_{2}\right)
$$

Resistance $R$ is expressed by only the variable $\left(x_{1}+x_{2}\right)$. Therefore, the total level of the pig iron and molten slag can be detected by measuring $R$.

\section{Online Test}

\subsection{Current Signal Pattern}

The detected voltage of the measurement is quite low from the result of numerical simulation. ${ }^{9)}$ In fact, the order of the detected voltage was $\mu \mathrm{V}$. Therefore, a pseudo random signal was adopted to improve the Signal to Noise $(\mathrm{S} / \mathrm{N})$ ratio.

The signal pattern of the current signal is shown in Fig. 2.

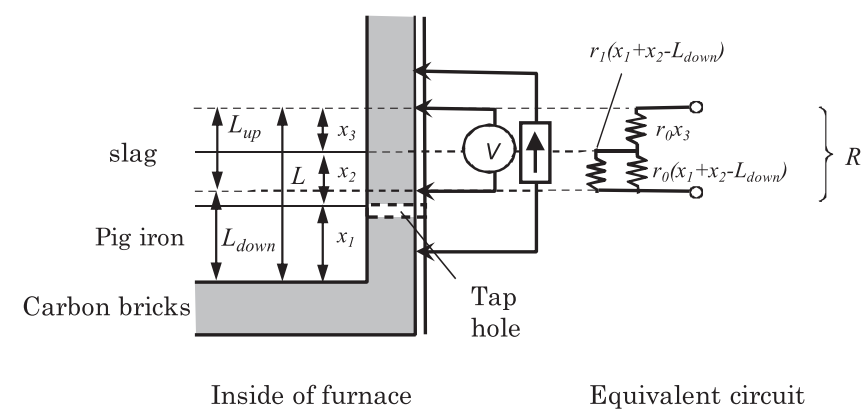

Fig. 1. Schematic diagram of the pig iron and molten slag measuring system.

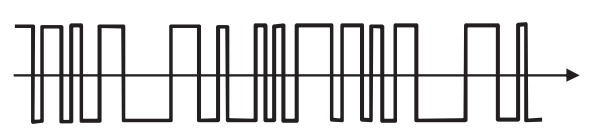

Pseudo random signal $(\mathrm{N}=127)$

Fig. 2. The signal pattern of the current signal.
A pseudo random signal is an artificial noise. The signal is periodic, but bits within a period are arrayed in the most random order. It can also be demodulated by a self-correlation calculation with an original pattern as a reference signal. The length of the pseudo random signal used in these experiments was 127 .

This method is expected to improve the $\mathrm{S} / \mathrm{N}$ ratio. Moreover, in principle, the result of self-correlation excludes the offset (for example, thermo-electro-motive force or EMF signal which can be regarded as a DC signal in the short term) included in the observed signal.

\subsection{Outline of Online Test}

An online test was performed at JFE Steel East Japan Works Keihin No. 2 blast furnace. As shown in Fig. 3, each electrode was set at 4 levels below the tuyere level. At each electrode position, a small hole was made in the steel shell for installation, and the tip of each electrode was set in physical contact with a carbon brick.

\subsection{One Point Measurement ${ }^{8,9)}$}

The online measurement started from simple single position measurement. Electrodes for measurements were set near No. 1 tap hole (Fig. 4).

Data were recorded at 1 minute intervals, and the obtained data were compared with the operational data. Since measurement was done using constant amplitude current, in Ohm's law, the obtained voltage has the same meaning as resistance. Therefore, the voltage data are presented below. The voltage data indicating the pig iron and molten slag level in the figure is shown upside-down on the longitudinal axis corresponding to the height of the level.

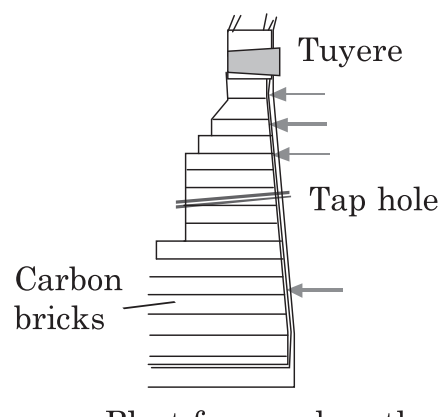

Arrows indicate positions of electrodes

Fig. 3. Electrodes position for measurement.

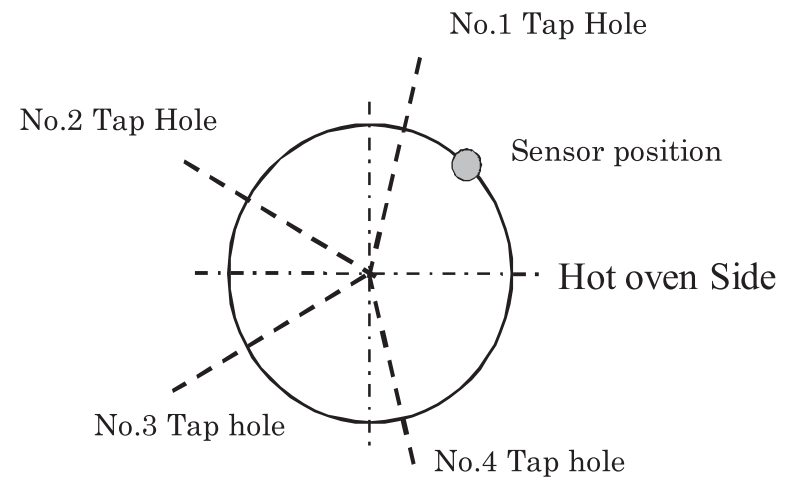

Fig. 4. Measure position. 
Although the absolute level cannot be obtained, level fluctuations can be obtained by comparing these data with the operational data.

Figure 5 is one of results when the level increased. The horizontal axis indicates time. Voltage data for a 48 hour period are shown. The permeability resistance index data are also shown. This index represents the furnace state, and a large index means that a furnace is in poor condition.

After about 24 hours, the permeability resistance index increased suddenly. When this condition occurs, the operator controls the productivity of pig iron and molten slag to decrease the index, and the index decreases in a short time, meaning the furnace condition recovers. On the other hand, the pig iron and molten slag level increases faster than the index data does, and then the level meter decreases with the index after low productivity operation.

These results show the possibility of preventing a furnace from falling into a poor condition by operation to reduce productivity or accelerate tapping of pig iron and molten slag by opening plural tap holes when the level data exceed the threshold.

In Fig. 5, the level data show a sudden increase and sudden decrease around 10 hours after the measurement starts. The cause of this phenomenon has not yet been clarified. At this furnace, tapping is usually performed using two of four tap holes, and the tap holes are opened by turns according to a rule. When the rule changes (this change is done regularly), operations become transitional. This phenomenon of sudden increase and decrease is observed when these transitional operations are applied. There seems to be a liquid flow in a blast furnace, so the data imply that the flow changes dramatically, and the level increases and decreases suddenly as a result.

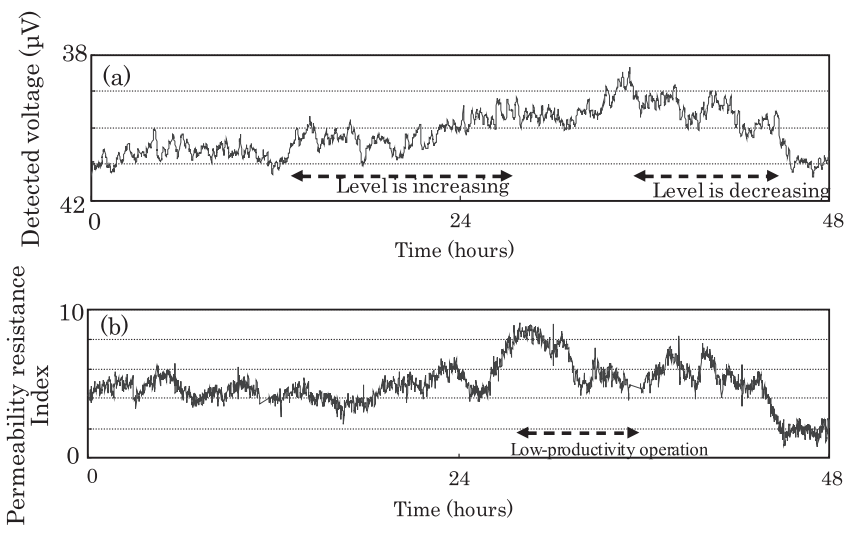

Fig. 5. Level data (a) and permeability resistance index data (b). ${ }^{9)}$

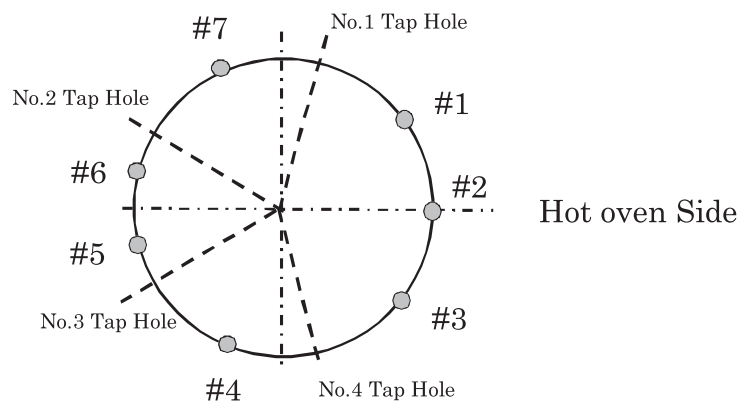

Fig. 6. Measure positions.

\subsection{Measurements at Plural Positions ${ }^{10)}$}

Next, plural positions measurements were tried to confirm whether the level difference occurred due to liquid flowing in the hearth. Four electrodes were set at each of 7 measurement positions along the circumference of the furnace. These measurement positions are shown in Fig. 6.

\subsection{Reduction of Noise}

It may be noted that the correlation between the level data and operational data sometimes became quite weak. This could be caused by variations in the offset voltage of the detected data. Since the number of -1 included in one cycle of the current pattern is always one more than that of 1 in pseudo random signal, the side lobe value is $-1 / \mathrm{N}$. However, if the offset in the detected voltage signal of a cycle is fluctuated, it gives rise to an uncertainty in the detected voltage. Therefore, both numbers in a cycle should be made the same. To satisfy this condition, the two phase modulated pseudo random signal was adopted. This signal pattern is shown in Fig. 7. This signal is made by dividing each bit of the original pseudo random signal into two parts, i.e., 1 in an original signal is divided into $-1,1$, and -1 in an original is divided into $1,-1$. The clock frequency of the two phase modulated pseudo random signal was $6 \mathrm{~Hz}$.

At first, the current signal was fed independently at each sensor position. As a result, electrical noises as shown Fig. 8 were found in the detected voltage signal pattern at each measurement position. This was another noise problem.

Original pseudo random signal (a part of 1 cycle)

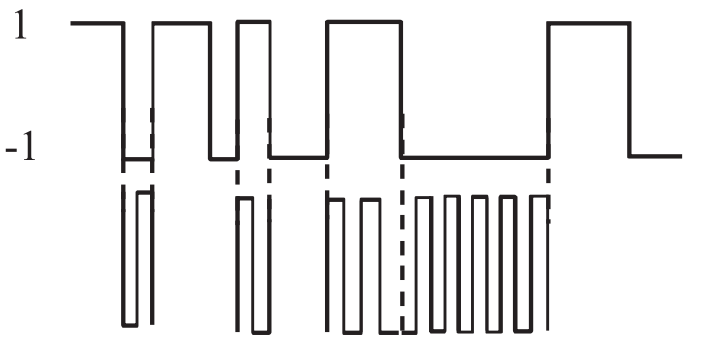

Each 1 bit divides into 2 value $(1,-1)$ or $(-1,1)$<smiles>C1=CCCC1</smiles>

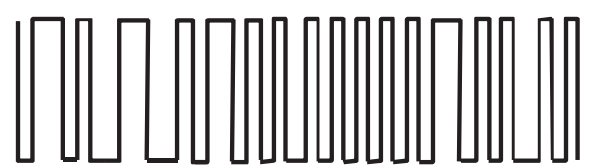

2 phase modulated pseudo random signal

Fig. 7. Modified current pattern.

Inductive noises from other measuring points

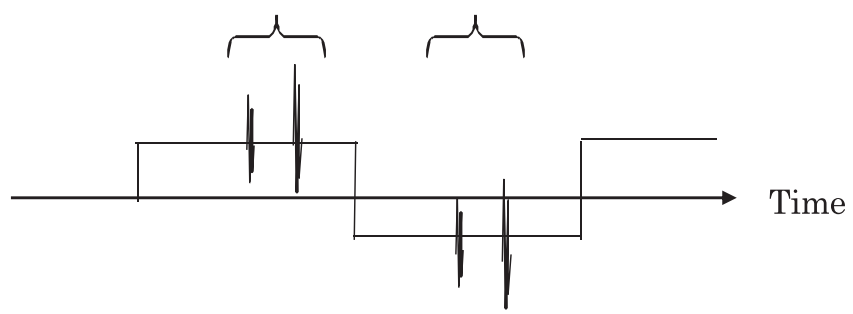

Fig. 8. Schematic diagram of noises on detected voltage pattern. 
From the result of the examination of these noises, when the noise is generated is coincident with the time when the polarity of the current pattern at a neighboring position is changed from + to - , or from - to + . To improve these noises, the current signal was fed synchronously. And then, noises are generated at the same time in the detected signal at all positions. The noise can be seen regularly in the detected signal when the polarity of the current pattern changes. Therefore, the noise can be removed by excluding sampled data during the fixed period before/after the polarity of the current changes, which can be regarded as the noise. Finally, it was confirmed that all noises had disappeared.

Following this improvement, the measured data were highly correlated with the operational data of the blast furnace.

\subsection{Results of Online Test}

The results described here are for operation when the order of opening tap hole was changed, and before and after the order changing. To compare the respective results, each datum was standardized by changing its width.

Figure 9 shows the level variation before/after the fluctuating furnace condition occurring during a special operation. A rise in the liquid level at all points was indicated before the furnace fluctuation began, and after operating the furnace to reduce productivity, all levels decreased. However, the changes were not similar at some sensor positions.

Another example is shown in Fig. 10. These results indicate the sign of the furnace fluctuation. In this case, although the furnace condition did not result in fluctuation, the level increased at some positions, and at other positions it did not change.

\section{Discussion}

In the second results, the changes in the liquid level seem to be consecutive in the circumference direction. In addition, the changes in the first example can be considered as well as those in the second. Those results mean that the liquid level was not identical, but was locally different in the blast furnace. Moreover, those results might indicate that flows in the furnace make the liquid level uniform was weak.

When there is ununiformity in a liquid level, the furnace condition easily fluctuates and this may possibly prevent stable operation. Therefore, if a large ununiformity of the liquid level occurs, stable operation can be continued by
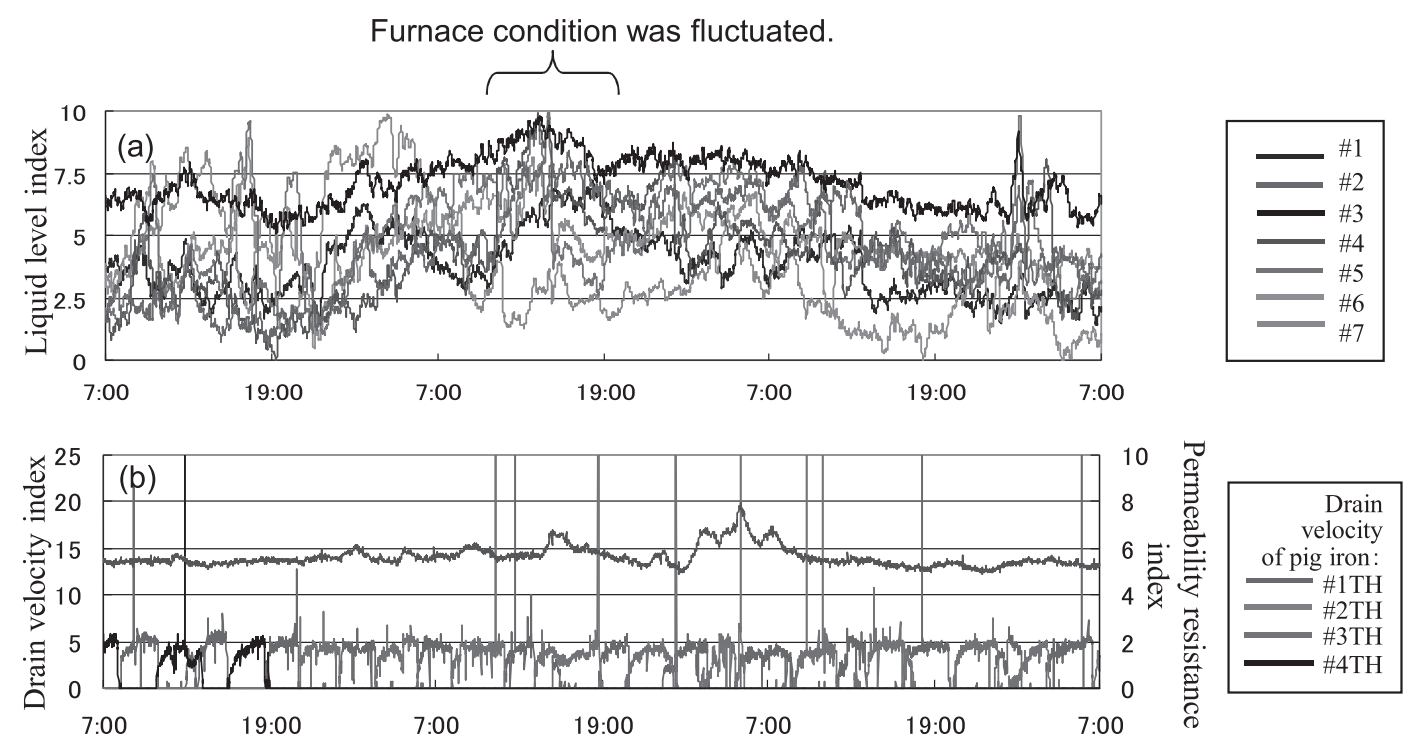

Fig. 9. Level data (a) and permeability resistance index and pig iron drainage index data (b).
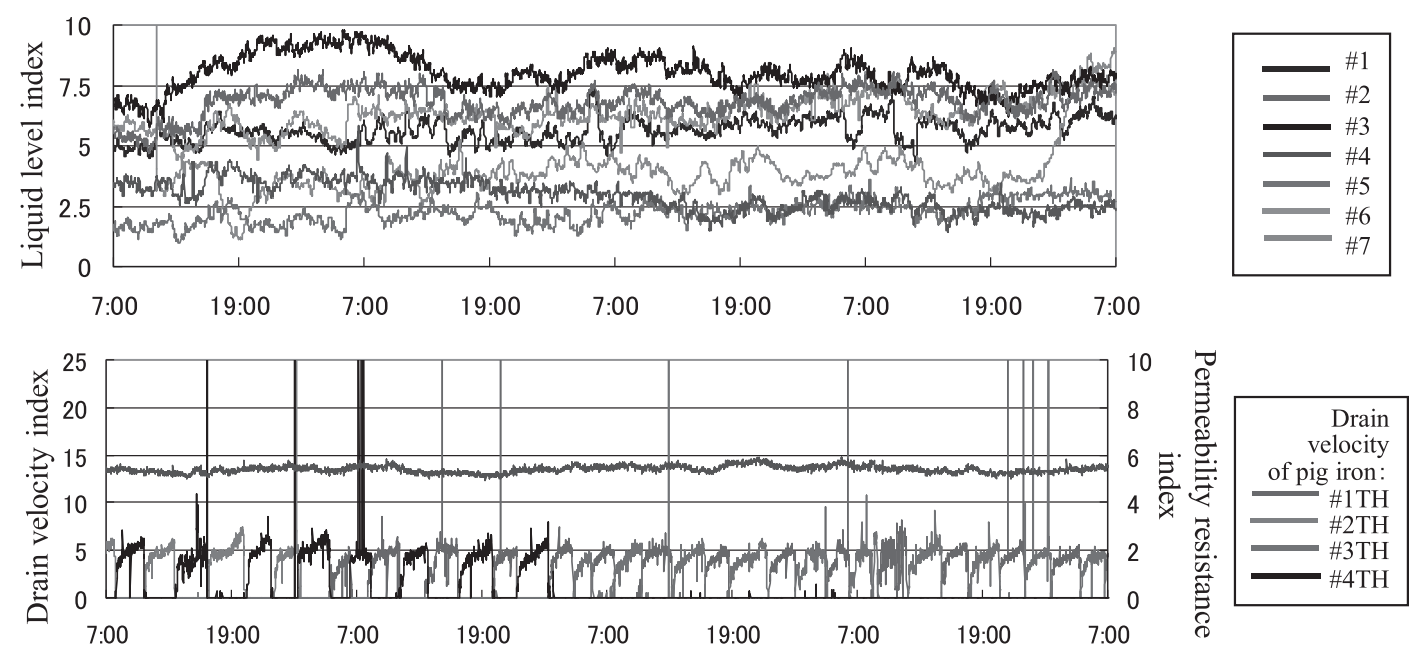

Fig. 10. Level data (a) and permeability resistance index and pig iron drainage index data (b). 
opening the nearest tap hole where the level meter indicates a higher level and draining pig iron and molten slag from that tap hole.

\section{Summary}

A pig iron and molten slag level meter was developed, in which the electrical resistance of the hearth of a blast furnace is measured by feeding a current to the bottom of the furnace. Online measurement was done at No. 2 blast furnace at JFE Steel East Japan Works (Keihin District) by installing electrodes at 7 measuring positions around the circumference of the furnace.

To improve the $\mathrm{S} / \mathrm{N}$ ratio, the two phase modulated pseudo random signal was adopted as the fed current pattern. However, independent feed of the current signal at each measurement position causes another noise problem. To reduce the noises in the detected voltage pattern, current signal is fed at the same time for each sensor position. Because the noises are generated at the same time at every position, the noises are easily removed by excluding data during the fixed period before/after the current polarity is changed. Finally, the noise problem was solved, and extremely small voltage measurements of the hearth of the blast furnace were achieved.

The results of the level measurements were consistent with the operational data. The level meter indicated that at every sensor position the liquid level increased, and then, after changing to low productivity operation, the level decreased. However, these changes were different depend- ing on the position. This means that the liquid level distributes along the circumference of the blast furnace.

\section{Future Work}

The effect of heat on resistance in blast furnace measurement has not yet been evaluated. In particular, temperature changes cause instability in the resistance of carbon bricks or stamping mixes is unstable by temperature changes.

Next, the measured liquid level will be visualized so that an operator can easily recognize whether the level is higher than usual or not, and increasing or not.

\section{REFERENCES}

1) P. K. Lebed, L. A. Safina, T. V. Demidenko, A. Y. Semenko and I. E. Pochekailo: Sov. Autom. Contr., 20 (1990), 76.

2) D. Lathlean, D. Mellor, S. Mitchell and F. Tanzil: Proc. McMaster Symp. on Raceway Control for Optimum Blast Furnace Performance, McMaster Univ., Ontario, (1991), 204.

3) O. Mielenz, A. Krüner, H. Köchner, H. P. Ruthner, M. Peters and P. Schmöle: Metal Plant Technol. Int., 30 (2007), 44.

4) H. Yokoyama, K. Kunitomo, M. Sugiura and K. Nakamura: CAMPISIJ, 17 (2004), 139.

5) H. Yokoyama and K. Kunitomo: CAMP-ISIJ, 18 (2005), 101.

6) S. A. Zaimi, G. Danloy, T. Campos, D. Pomeroy, M. Bennani, R. Perez-Chust, B. Lecacheux and D. Huang: Proc. Int. Symp. Recent Progress on Mathematical Modeling in Ironmaking 2008, ISIJ, Tokyo, (2008), 20.

7) G. Danloy, C. Stolz, J. Crahay and P. Dubois: Proc. 58th Ironmaking Conf., ISS, Warrendale, PA, (1999), 89.

8) T. Ito, J. Yotsuji and A. Nagamune: CAMP-ISIJ, 24 (2011), 889, CDROM.

9) T. Ito, J. Yotsuji and A. Nagamune: Paper Summary of 21st ANST Conf, ASNT, Columbus, OH, (2012), 111, CD-ROM.

10) T. Ito, J. Yotsuji and A. Nagamune: CAMP-ISIJ, 27 (2014), 327, CDROM. 